\title{
EL PODER Y LA DOMINACIÓN MASCULINA EN EL UNIVERSO DE ZOLA
}

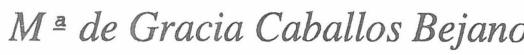

\begin{abstract}
In this essay, which can be considered as a complement to a previous one dealing with the woman in Zola's work, I try to explain the male concept within Zola's philosophy. For that purpose, I have made a diachronic study about the concept of man in different authors and moments in history, specially in the XIX century french society and focusing on male aspects such as action, possession and brutalization, specifically emphatized by the power of sexuality. These caracteristics, in Zola's work, together with the wide range of male actantcs, have been studied in four states: aristocracy, middle class, clergy and proletariat. In conclusion, under Zola's point of wiew, since the moment in which man appeared in nature, he has only had one principle: he is the center of creation and all other beings, including women, are centered around him.
\end{abstract}

Antes de comenzar nuestro estudio sobre el hombre, el de Zola en particular, vamos a partir de una cita de Diderot: El hombre es un conjunto de fuerza y debilidad, de luz y de ceguera, de pequeñez y grandeza $a^{1}$; vamos a descubrir cómo, a pesar de la clase social en que se ubique, a pesar del medio en que se encuentre, a pesar de la educación que tenga, los diferentes hombres que vamos a describir son caracterizados como el cúmulo de los principios expuestos en ella.

Si recordamos, en primer lugar, la definición que en su obra Repertorio universal de mujeres célebres (1827), Louis Marie Prudhomme nos da del hombre, éste es considerado principalmente como un poder de acción $n^{2}$, mientras que la mujer, es concebida como un poder de fascinación $n^{3}$. Este primer concepto, quizás el más superficial que encontramos en Zola sobre la diferencia entre lo masculino y lo femenino, nos muestra ya, aunque sólo sea de manera intrínseca, la fuerza y el poder que conlleva lo masculino ${ }^{4}$.

\footnotetext{
${ }^{1}$ LAURENT, A.: 1989, Frases célebres, Edicomunicación, S.A., Barcelona, p. 95.

${ }^{2}$ Debemos señalar que la fuerza y la acción no son sólo en Zola símbolo de la fuerza física, sino de moral y de integridad. Para él, la idea de compromiso y el sentido del deber son lo que hacen grande al hombre: il n'a aucune sympathie pour ceux qui se contentent de rester de simples spectateurs (MULLER-CAMPBELL, 1973, p. 170). Sobre el tema de la culpabilidad, debilidad y falta de acción masculina y el menosprecio del poder paterno en su obra, confrontar: MULLER-CAMPBELL, Denise E.: 1973, Le thème de la culpabilité masculine dans l'oeuvre d'Émile Zola, Les Cahiers Naturalistes, Fasquelle, París, vol, 19, n1 46, pp. 165-181.

${ }^{3}$ Hasta bien entrado el siglo XIX, el concepto de mujer intelectual o comprometida, desde un punto de vista cultural o político, va contra el concepto de fecundidad y de feminidad. Estos testimonios de carácter negativo los encontramos Lanto en el campo de la filosofía, Nietzsche, de la medicina, Paul J. Möbius, o de la litcratura, Julcs Michelet.

${ }^{4}$ En La faute de l'abbé Mouret, Zola nos da una especie de manual de conducta del hombre en relación a su
} 
El filósofo Carmelo Monedero, intenta evitar comparaciones sobre el hombre y centra su estudio en el hombre mismo, creyendo que es la vía más segura para poder conocerlo en profundidad. Este autor cree que ser hombre es: ... constituir un mundo objetivo interpersonal y resentirse de la ubicación en él ${ }^{5}$. El hombre, desde el principio de los tiempos, se cree un ser superior y, por ello, intenta crear a su alrededor un mundo que gire en torno a él y del cual él será el único conductor. Pero, pronto también, percibe su situación irrelevante en medio de ese mundo y, como consecuencia, todo esto le sumirá en una gran desesperación.

Protágoras, sin embargo, profundiza aún más en su concepción del hombre y lo define como: la medida de todas las cosas; de las que son, en tanto que son, y de las que no son, en tanto que no son. Para el sofista griego, las cosas, Khrémata, tienen el sentido de las cosas de la vida, de aquellas de las que se ocupan los hombres. Como Julián Marías nos indica también al analizar las teorías de este filósofo, es el hombre el encargado de encontrar el sentido, la función y la medida de las $\cos ^{6}{ }^{6}$.

Sin embargo la sociedad, en su devenir, no sólo no ha sabido valorar y mantener el verdadero sentido de estos conceptos sino que incluso los ha invertido, haciendo que las cosas y su posesión sean el verdadero centro de la existencia y que el hombre sea interpretado, categorizado y medido desde ellas.

Desde que las sociedades se mercantilizaron, este concepto y esta visión del hombre como ser capaz de acaparar cosas ha ido en aumento, siendo medido sólo por su capacidad de acaparación de poder físico, político o económico y no por su humanidad y, en especial, a partir de la mercantilización de la sociedad, por las cosas que le rodean, que posee, que hace o que le faltan. Todo esto nos lleva a connotar al hombre, según nos dice Antonio Núñez C. de Herrera, por el rastro que deja, significándolo como: un animal ruidoso que pone su inteligencia al servicio de la sonoridad y del escándalo?.

\footnotetext{
compañera, en boca del abate Mouret:

Vous l'aimerez, parce qu'elle est votre chair elle-même, votre sang et vos os.

Vous la protégerez... Rappelez-vous qu'elle vous est confiée; elle est la

soumission et la faiblesse... Et que vous soyez damné si vous la délaissez.jamais!

Ce serait le plus lâche abandon que Dieu eût à punir. Dès qu'elle s'est donnée

(envuelta en su poder de fascinación), elle est vôtre pour toujours (Zola, 1971, p. 295).
}

En un artículo aparecido en Le Figaro el 18 de abril de 1881, titulado Nos femmes, Zola avanza áun más en sus ideas y no admite que la mujer sea considerada únicamente por su poder de fascinación ni que sea vista como un objeto de placer y de lujo, sino que considera que debe ser admitida como una compañera e incluso como una colaboradora. Él ve a la mujer como: un être capable d'assumer des responsabilités et de partager pleinement et activement la vie de l'homme (MULLER-CAMPBELL, 1973, p. 180).

\footnotetext{
${ }_{5}^{5}$ MONEDERO, Carmelo: 1995, Antropología y psicología, Pirámide, Madrid, p. 52.

${ }^{6}$ Confrontar MARIAS, Julián: Biografía de la filosofía. Confrontar también el artículo del mismo autor aparecido en cl diario $\mathrm{ABC}$, el 24 de julic de 1997 , titulado: La medida dol hombre

${ }^{7}$ Antonio Núñez C. de Herrera, Sobre el ruido, Revista Ateneo, año IV, n1 40, noviembre 1927, Jerez de la Frontera.
} 
Todos los rasgos ya explicitados los apreciamos claramente en el hombre de mediados del siglo XIX y, particularmente también, en la visión masculina de los personajes de Zola.

En la documentación preparatoria para la elaboración de su novela L'argent, define el dinero como algo que no es ni bueno ni malo, hoy en día casi imprescindible, un medio que posibilita el alcance de todos los deseos y que, incluso, puede dignificar al hombre: l'argent est devenu pour beaucoup la dignité de la vie: il rend libre, est l'hygiène, la propreté, la santé, presque l'intelligence ${ }^{8}$. Es conveniente aclarar que, en la obra de Zola, al contrario que el hombre, ninguna mujer ha conseguido su libertad por medio del dinero. Thérèse Moreau, del estudio de la obra de Zola, extrae que para él: la femme est nécessaire à la naissance et à la production du capital, mais elle ne doit pas en être la maîtresse, ni en avoir la jouissance.

Evidenciamos aquí una concepción empírica del hombre en la que, además, aparece desposeído de todo su contenido humano y donde, como algo innato, su faceta animal rebrota de nuevo desde su origen más cavernario. La ejemplificación plástica de este hombre animalizado la encontramos ya en la Roma clásica en la frase de Plauto: el hombre es un lobo para el hombre. Esta misma tesis ha sido repetida posteriormente en el s. XVII, por el filósofo Thomas Hobbes. Éste especifica que dentro de la naturaleza del hombre hay tres causas que le impulsan a la beligerancia y desarrollan su instinto animal: primera. la competencia; segunda, la desconfianza; tercera, la gloria ${ }^{10}$.

El hombre-animal establece a su alrededor una red simbólica de carácter degradatorio entre el yo y el otro ${ }^{11}$, que gira en torno a la lucha y a la explotación del otro, y del que, como objetivo final, pretende aprovecharse, como un parásito cualquiera, llevándolo a la ruina y al aniquilamiento: es, como hemos indicado anteriormente, la explotación del hombre por el hombre.

De este origen animal, dominador y cruel, le es difícil al hombre desprenderse, evidenciándose esto de una forma clara en la relación sexual, como nos lo muestra primeramente Betcherev en su teoría de las dominantes reflejas ${ }^{12}$ y posteriormente Durand.

\footnotetext{
${ }^{8}$ MOREAU, Thérèse: 1983, Noces d'or: l'économie anti-malthusienne dans l'oeuvre de Zola, Romantisme, n1 40, p. 153.

${ }^{9}$ Ibidem, p. 160. Ver también, de la misma autora, Le sang de l'histoire, Flammarion, París, 1982.

${ }^{10}$ HOBBES, Thomas: 1965, Antología: Del ciudadano. Leviatán. Tecnos, Madrid, pp. 135-136. Thomas Hobbes en su obra El Leviatan (1651), indica que, en estado de naturaleza, el hombre, dominado pos los deseos, se aproxima lo más posible a su origen animal y salvaje; en él, todos los hombres tienen derecho a todo, es la guerra de todos contra todos. Como vemos, esta idea destructiva y negativa de la naturaleza y de su primer agente nocivo, el hombre, aunque aflora de nuevo en este período, no es nueva del siglo XIX, sino que está patente ya desde el origen de los tiempos. Esto, aplicado también a la sociedad, nos aparece explicitado en el siglo XVIII en la obra de Diderot: Dans la nature, toutes les espèces se dévorent, toutes les conditions se dévorent dans la société (DIDEROT, Denis: Le neveu de Rameau, Droz, París, p. 124).

${ }^{11}$ Para Gilbert Durand, mientras más animaliza el hombre sus pensamientos y sus ideas, más estas se inadaptan, se bloquean y envejecen. Este proceso de animalización lleva emparejado un deseo de huida que, unido a un proceso violento, tiene un carácter marcadamente negativo.

${ }^{12}$ Para Betcherev (seguidor de las teorías de los reflejos condicionados de Pavlov y de su transformación, por
} 
A lo largo del estudio de las diferentes facetas del hombre zoliano ${ }^{13}$, vamos a ver cómo lo expuesto anteriormente, es decir, los aspectos de acción, de posesión y de animalización, potenciados por la fuerza avasalladora de la sexualidad ${ }^{14}$, se patentizan en su obra, degenerando, generalmente por causas genéticas, hacia matices esclavizadores, criminales e incluso autodestructivos ${ }^{15}$.

evolución y adaptacion al medio, en reflejo innato o primario) toda la actividad del hombre, desde su nacimiento, está regida por las dominantes reflejas, innatas en él. La tercera de ellas, la sexual, estudiada ya por Oufland en los animales, es de origen interno y se pone en marcha cuando aparece el celo y las secreciones hormonales. Esto, aplicado al hombre, deja patente su carácter cíclico, su motivación interna y su influencia dominante en el animal humano. La teoría de las dominantes reflejas son también la base del pensamiento de Gilbert Durand. Confontar BETCHEREV, W.: 1933, General principes of human reflexology y DURAND, Gilbert: 1969, Les structutures anthropologiques de l'imaginaire, Bordas, París.

${ }^{13}$ En este trabajo vamos a tomar al hombre como ser adulto, separándolo de su etapa infantil que raramente nos es descrita con detalle en este escritor. En general, cuando aparece el niño, se nos muestra la importancia que tiene para el temperamento de este ser los primeros años de su vida. Zola, al igual que Daudet, Maupassant o Mirbeau, culpan a los sucesivos gobiernos franceses y a las normas educacionales que imponen, del empobrecimiento y del agotamiento de sus niños. Según nos indica Marius-Ary Leblond en su libro La Société Française sous la troisième République, d'après les romanciers contemporains, la sociedad: ... rend (l'homme) médiocre parce qu'elle lui impose, ... une éducation uniforme et étroite qui est une sorte d'internat intellectuel (1905, p. 48). Zola, haciendo suyas las ideas de Rousseau, predica que el niño para salvarse tiene que volver a una educación natural. Sin embargo, y a pesar de su carácter misógeno, en La joie de vivre, encarna el Émile naturalista no en un personaje masculino, sino en la figura de la huérfana Pauline, su ideal pedagógico. Zola, en particular al final de su producción, se convierte en un demógrafo y en un sociólogo, va contra las teorías malthusianas -considera a Malthus como el precursor del pesimismo social moderno-, defendidas por las clases dirigentes y por los poderosos -los acusa de ser la causa de la descomposición de un sistema basado en el egoísmo y en la explotación del más débil-. La culminación de estas teorías degradatorias, puestas en funcionamiento por la sociedad industrial del s. XIX y descritas clínicamente en los 20 volúmenes de Les Rougon-Macquart, se encuentra en Fécondité, canto a la vida natural, sin ataduras, personificado en la pareja formada por Mathieu y Marianne Froment, origen de una nueva humanidad. Su intención primaria en esta obra, es discernir las causas que han conducido a este caos y poner, a través de esta pareja y de su familia, las indicaciones terapeúticas necesarias para dar un diagnóstico preciso y mostrar una solución, extendiendo por el mundo el Evangelio y las consecuencias de la Fecundidad.

${ }^{14}$ Jean Borie en su libro Zola et les mythes, nos muestra que el universo zoliano está completamente sexualizado y esta sexualidad tiene marcados rasgos negativos y destructivos: Toutes les formes possibles de la sexualité prennent uniformement un caractère destructeur (1971, p. 63).

${ }^{15} \mathrm{La}$ influencia dominadora del hombre sobre todo lo que le rodea, es un hecho típico de la narrativa de este escritor en la que el hombre débil es siempre relegado por otro o sometido por su mujer. Podemos apreciar que esta fuerza masculina que Zola despliega en sus actantes y que él mismo ejemplifica en su relación con Jeanne Rozerot, es el reflejo opuesto de la triple dominación femenina (abuela, madre y mujer) que él ha soportado a lo largo de su vida, a causa de la temprana muerte de su padre y del único espejo que tenía para reflejarse: su abuelo materno Aubert; es un hombre bueno pero impotente, sin capacidad de poner nada en marcha y dominado por su mujer Émilie Aubert. Muller-Campbell nos muestra cómo encontramos con facilidad en Zola: un caractère féminant puissant, dominant et s'opposant à une personnalité masculine hésitante (1973, p. 168). Estos actantes masculinos, denominados antihéroes, están caracterizados por su debilidad y por estar sometidos a una mujer, son abandonados generalmente al aparecer otro hombre con las dotes hombriles necesarias de virilidad y de dinamismo. Estas peculiaridades de debilidad masculina, aparecen en todas las obras anteriores a 1869 e igualmente en la serie de Les Rougon-Macquart, en la que florecen los denominados "ménage à trois": François Mouret, Marthe, l'abbé Faujas, en La conquête de Plassans; Coupeau, Gervaise, Lantier, en L'Assommoir; Roubaud, Séverine, Jacques, en La bête humaine; e incluso permitiendo el lesbianismo, Muffat, Nana, Satin, en Nana. Podemos también señalar, como consecuencia de su temprana horfandad, que la carencia de afecto y poder paterno se patentiza en Les Rougon-Macquart. F. W. J. Hemmings indica que es difícil encontrar en esta serie a un padre que cumpla con sus deberes paternos. Confrontar, HEMMINGS, F. W. J.: 1966, Émile Zola, Clarendon Press, 20 edición, Oxford, p. 6. 
Para comprender a este hombre descrito e imaginado por Zola ${ }^{16}$, vamos primero a recordar cómo era el reparto social en Francia, en el s. XIX, después de los diferentes avatares políticos acaecidos.

Como consecuencia de la Revolución de 1789, el orden social establecido hasta el momento había sufrido profundos cambios. El clero y la nobleza pierden casi todo su poder en detrimento de la burguesía, clase social en alza, protegida por Napoleón I. El orden jerárquico se establece alrededor del poder económico: el dinero es el rey. Esto lleva a una relajación de las costumbres y a una decadencia social que se patentiza particularmente a partir de mediados de siglo ${ }^{17}$.

Con la restauración, la nobleza intenta recuperar el poder perdido y sus privilegios, pero sólo lo consigue a medias, en el campo, acaparando posesiones, y en el terreno administrativo, ocupando los altos puestos de la Administración.

En el último tercio del s. XIX, la nobleza, para conseguir dinero y poder, se alía, por matrimonios, con jóvenes herederos de la alta burguesía, pero, a causa de su inadaptación, se ve definitivamente relegada al ostracismo si no está respaldada por un fuerte capital. En consecuencia, podemos deducir que la nobleza de casta ha desaparecido y que la que subsiste engloba a gentes de todos los estamentos sociales que han accedido a ella por medio del dinero. A mediados de siglo, según Marius-Ary Leblond, podemos encontrar seis tipos de nobleza: la noblesse marronne de la Troisième République, la noblesse papale, la noblesse orléaniste, la:noblesse légitimée de la Restauration, la noblesse de l'Empire, enfin les restes de l'ancienne noblesse de royautét ${ }^{18}$.

Para conseguir subsistir, la nobleza busca apoyo en su aliado natural, el clero, aunque este estamento se encuentre envejecido y capidisminuido ya desde 1830 .

El Estado faculta el rejuvenecimiento del clero, proporcionando ayudas al estudio, en particular a los jóvenes que provienen del medio rural. El clero quiere apoderarse de la educación de los jóvenes, como medio de dominar el poder y, en especial, de la enseñanza universitaria, desde donde podrá influir en los futuros políticos y en los hombres que van a detentar el poder financiero e industrial.

Tanto Louis-Philippe como Napoleón III $^{19}$, buscan su cooperación y le conceden becas de formación, porque este estamento le ayuda a mantener el poder, el orden y la obediencia del pueblo.

\footnotetext{
${ }^{16}$ Zola en su Roman expérimental, nos indica que el escritor naturalista nunca debe pronunciarse sobre ningún aspecto; su función primordial es examinar, describir y decir cómo son las cosas; el público es el que debe sacar las conclusiones. Confrontar FOREST, Annie: 1981, La violence dans Les Rougon-Macquart, thèse de 3e. cycle, Université Lyon II.

${ }^{17}$ Confrontar DETHLOFF, Uwe: 1987, Emancipation sociale et patriarcat utopique, Kwartalnik Neofilologiczny, Polonia, vol. 34, n1 2, pp. 131-144.

${ }^{18}$ LEBLOND, Marius-Ary, 1905, op. cit., p. 138.

${ }^{19}$ Zola califica a Napoleón III como: Moyenne des intelligences de son temps. Héritier naïf d'une légende, il ne l'a pas troublée par une individualité; y la sociedad que él defiende es definida por el escritor en La curée, como: Le triomphe
} 
La burguesía, aunque no en su totalidad, es la clase más favorecida por la Revolución, y en particular a partir de la época imperial; es la clase social de los nuevos ricos. En general, acceden a ella por dos vías: la adquisición a bajo precio de los bienes nacionales o por los beneficios que extraen de la guerra, ya que ésta conlleva unos problemas de carencia que solventan para sus propios beneficios, por medio de la especulación ${ }^{20}$.

Al lado de esta alta burguesía está la burguesía industrial y financiera que asciende rápidamente por dos razones:

1.- Por la llegada de dinero a mediados de siglo; este hecho hace subir los precios un veinte por ciento. Las fortunas se revalorizan entre 1850 y 1870 en casi un treinta por ciento.

2.- El saintsimonismo resalta la importancia de los productores y de la clase industrial como sustentadora de la sociedad. Saint-Simon indica que la edad de oro de la humanidad está en el futuro y no en el pasado. La prosperidad se hace patente en estos momentos gracias a los créditos, pero la especulación se desata y la concentración de los poderes en manos de una oligarquía es condenada por Proudhon y sus seguidores.

Esta concentración de poderes y de riqueza en esta burguesía industrial se ve favorecida doblemente: por une parte por la política matrimonial que tiende a concentrar riquezas y poder en pocas manos, y, por otra parte, por la reducción, al mismo tiempo, del número de hijos por matrimonio -ideología malthusiana- para evitar la dispersión de las fortunas.

La divisa de esta clase, pacífica por conveniencia, es disfrutar del monopolio de la economía, de la riqueza y de la instrucción.

El proletariado es una clase en alza en todo el siglo XIX, y en particular desde 1850, a causa del desarrollo industrial. Hay específicamente dos tipos:

1.- Los que provienen del sector artesanal. Son tranquilos, estables, cualificados, abiertos a los problemas de su tiempo, aman la lectura y buscan la formación superior de sus hijos.

2.- Los obreros industriales. Proceden de los medios rurales, sin ninguna cualificación profesional, y emigran a la ciudad para acceder a mejores salarios. Pero, por la carencia de esta especialización, los salarios son bajos, los precios altos y los alojamientos escasos; a causa de ello son atraídos con facilidad por grupos de ideas socializantes y se inclinan rápidamente hacia el terreno de la indisciplina social.

\footnotetext{
de l'immoralité, l'union du jeu et de la débauche.

${ }^{20}$ Leblond, sobre la preponderancia de la burguesía adinerada en este período dice: En une monarchie démocratique comme le Second Empire, il n'y a ... que l'homme de guerre et l'homme d'argent, tous deux s'entendant pour mieux dominer (op. cit. p. 107).
} 
Esta situación se agrava aún más a partir de la mitad de siglo: los salarios bajan, los precios se mantienen, el paro aumenta, las condiciones de trabajo y de higiene son casi inhumanas y la prostitución se extiende en las ciudades como único medio de sustento familiar.

Un decreto del 2 de marzo de 1878, establece la jornada máxima de once horas en provincia y diez en París.

En relación a los derechos políticos de esta clase, los obreros no suelen estar unidos, pero a partir de 1868, con la tolerancia a los sindicatos obreros y la creación de la primera Internacional Francesa que intenta inclinar a sus miembros hacia la acción revolucionaria, se unen y comienzan las etapas de huelgas para conseguir mejorar la condición de los obreros $^{21}$.

Después de la Revolución de 1789, Francia es aún un país eminentemente agrícola, debido a la abolición de los derechos feudales y a la venta de los bienes nacionales a los que todos tienen acceso. Pero esta mejora es efímera puesto que, por el alto endeudamiento y el alza de los precios, deben revender a las clases más pudientes. Hacia 1850, los campesinos representan la mitad de la población activa y hay que esperar al final de siglo para que el orden se invierta hacia el proletariado.

Los campesinos y toda su familia viven de la tierra y se endeudan para comprar más tierras; sin embargo no mejoran los bienes de equipo y, en vez de enriquecerse, como no evolucionan industrialmente y mantienen los medios tradicionales de cultivo, los resultados son escasos y las deudas se acrecientan, debiendo vender y emigrar a los núcleos industriales.

A causa de su dedicación al trabajo, esta población está poco instruida, siendo analfabeta en 1832, el treinta y dos por ciento de ella. Contra esta situación se decretan, en 1833, las primeras Leyes de Educación Obligatoria. En 1881, la educación es obligatoria para los dos sexos desde los 6 a los 13 años, bajando la cota de analfabetismo en 1892 al quince por ciento.

A fines de siglo, las profesiones artesanales disminuyen frente a la proliferación de las profesiones liberales, surgiendo nuevas clases sociales en torno al mundo de la educación y de la instrucción. El comercio está en auge por el desarrollo de los transportes y el funcionariado, hasta ahora inaccesible, se abre a las clases populares.

El pequeño campesino, para defenderse de los grandes propietarios, se organiza en cooperativas y se tecnifica, llegando incluso a competir con él.

\footnotetext{
${ }^{21}$ Carlos Marx dice que Proudhon es una de las figuras más representativas que marca el socialismo francés al final de la monarquía de Julio, indica que:... il est l'un de ceux qui ont fait prendre à la classe ouvrière conscience d'ellemême( JARDIN, A., 1973, p. 216). Su divisa, en la memoria de 1840 denominada, Qu'est-ce que la propriété ? ou recherche sur le principe du droit et du gouvernement, es la frase: Dieu c'est le mal, la propriété c'est le vol (Ibidem, p. 217).
} 
En todas las clases sociales hay un movimiento de descristianización. En el campo esto se particulariza entre los hombres, debido al desarrollo de las ideas positivistas ${ }^{22}$.

Podemos concluir diciendo, como Jean-Marie Mayeur, que la sociedad francesa de fines de siglo tiende hacia el radicalismo anticlerical y hacia las ideas políticas de izquierda.

Después de aclarar esta organización estamental, vamos a buscar, en la obra narrativa de Zola, los arquetipos sociales masculinos que ejemplarizan estos rasgos generacionales, englobándolos igualmente dentro de estos cuatro apartados: la aristocracia, la alta burguesía, el clero y el proletariado.

No debemos perder de vista que el fin primordial de la obra de Zola es evidenciar por una parte una visión de la historia, de la sociedad y del hombre a través de la naturaleza, mostrándonos, al mismo tiempo, la interferencia directa que existe entre los elementos fundamentales naturales y la existencia de la vida.

a.- La aristocracia. Dentro de la escala social, es la clase a la que Zola presta menos atención, considerándola como una clase caduca, sin posible superación, que vive apoyada en sus antiguos privilegios, ya perdidos, y sin conciencia de poder. Está sujeta a una serie de reglas y normas sociales que la encorsetan y le impiden evolucionar.

Entre los varios tipos ejemplificados vamos a centrarnos en tres: Eugène Rougon, ministro de Napoleón III, el conde Muffat de Beuville y su suegro, el marqués de Chouard.

Eugène Rougon, orgulloso de su persona, es un ejemplo claro de la búsqueda del poder y de la dominación; no es noble por nacimiento sino por los servicios prestados al Imperio. Consigue su éxito social al acceder a la aristocracia por su casamiento con Véronique Beulin d'Orchères y su éxito profesional al ser nombrado ministro de Napoleón III. Aprovecha estos hechos para conseguir a todas las mujeres que se ponen a su paso, para mostrar la riqueza y el poder que ha adquirido y, apoyándose en el clima de corrupción existente, para ayudar a su familia y a sus amigos, concediendo dádivas y prebendas, siendo así alabado por todos. Todo esto se resume en Son Excellence Eugène Rougon: C'était, chez lui, un amour du pouvoir pour le pouvoir, ...il ne devenait véritablement supérieur que par ses besoins de domination. Là, il aimait son effort, il idolâtrait son intelligence... Il ne croyait qu'en lui, ... subordonnait tout à l'élargissement continu de sa personnalitê23. Como vemos, Eugène Rougon es el clásico ejemplo de macho dominante y egocéntrico, que alardea de su inteligencia y de su vitalidad como fuente de posesión y de sumisión.

22 Confrontar: JARDIN, A. y TUDESQ, A. J.: 1973, La France des notables. L'évolution générale, 1815-1848. Nouvelle Histoire de la France contemporaine, vol. 6, Seuil, París. AGULHON, Maurice: 1973, 1848 ou l'apprentissage de la république, 1848-1852. Nouvelle Histoire de la France contemporaine, vol. 8, Seuil, París. PLESSIS, Alain: 1973, De la fête impériale au mur des fédéres, 1852-1871, Nouvelle Histoire de la France contemporaine, vol. 9, Seuil, París. MAYEUR, Jean-Marie: 1973, Les débuts de la IIIe république, 1871-1898. Nouvelle Histoire de la France contemporaine, vol. 10, Seuil, París. RUBÉRIOUX, Madeleine: 1975, La république radicale, 1898-1914. Nouvelle Histoire de la France contemporaine, vol. 11, Seuil, París.

${ }^{23}$ ZOLA, Émile: 1971, Son excellence Eugène Rougon, Brodard et Taupin, Fasquelle, Le Livre de Poche, n1901, París, p. 152. 
El conde Muffat de Beuville -el título llega a la familia en la época del padre del conde, general de Napoleón I, ennoblecido por sus servicios-, es el representante del partido oficialista, que ocupa un alto cargo en el gobierno imperial.

Es un hombre severo y riguroso en su trabajo y sus costumbres, habituado a la vida familiar en su sentido más tradicional, que se refugia en la religión como escape a la monotonía de la vida y a la rigidez social en la que está inmerso: Il grandissait, il vieillissait, ignorant de la chair, plié à de rigides pratiques religieuses, ayant reglé sa vie sur des pretextes et des lois ${ }^{24}$.

Al conocer a Nana, en plena madurez, se despierta en él su juventud perdida y se deshonra, abandonando su trabajo, su casa y su familia para caer en los brazos de su amante: Il en arrivait maintenent à une passion exclusive, une de ces passions d'hommes qui n'ont pas eu de jeunesse. Il aimait Nana avec un besoin de la savoir à lui seul, de l'entendre, de la toucher, d'être dans son haleine ${ }^{25}$.

$\mathrm{Su}$ vida, al caer ante los requerimientos y la fuerza de la pasión, gira, a partir de ese momento, en torno a una ambivalencia: interiormente lucha entre sus deseos de amante y sus deberes de esposo y padre, con etapas oscuras considerads como de un misticismo religioso: Il pratiquait de nouveau, se confessait et communiait ...il offrait au ciel, comme une souffrance expiatrice, l'abominable tourment dont il souffrait... il montait son calvaire de croyant... tombé dans la sensualité enragée d'une fille ${ }^{26}$; exteriormente, sin embargo, mantiene la apariencia noble y tranquila a la que está habituado.

El marqués de Chouard, suegro del conde Muffat, es el representante del partido legitimista u orleanista, que encarna a la nobleza más tradicional. Sin embargo, frente a sus rígidos principios de clase, es una persona con los más bajos instintos animales y que soporta todo con tal de satisfacer sus libidinosas necesidades: Un soir, en venant prendre Satin, (Nana) reconnut le marquis de Chouard qui descendait l'escalier, les jambes cassées, se traînant sur la rampe, avec une figure blanche... elle trouvait Satin dans une saleté affreuse,... un lit infect, des pots qui traînaient, ... il revenait de temps à autre; mais il l'assommait, il reniflait dans tous les endroits pas propres, jusque dans ses pantoufles ${ }^{27}$.

Ambos, personajes de la obra Nana, sujetos a una férrea disciplina y a una ferrea educación austera que no deja aflorar sus instintos más primitivos, son el símbolo de la vieja nobleza que, en una continua vorágine de vicios y lujurias desenfrenadas, transgreden las normas, malgastando su fortuna y su patrimonio.

b.= La alta burguesía. Este estamento social es el que sufre más modificaciones a lo largo de todo el siglo y es el causante, por la relajación de costumbres, la falta de integridad y la depravación social en la que cae -según Dethloff, a causa del dinero y del poder que

\footnotetext{
${ }^{24}$ ZOLA, Émile: 1971, Nana, Brodard y Taupin, París, p. 138.

${ }^{25}$ Ibidem, p. 398.

${ }^{26}$ Ibidem, p. 398.

${ }^{27}$ Ibidem, p. 249.
} 
acapara y de los múltiples intereses personales y hedonistas-, de la pérdida del poder patriarcal y del desenfreno, no sólo de la burguesía, sino también del proletariado.

El 6 de noviembre de 1871, aparece en el periódico La cloche, una carta de Zola a su director Louis Ulbach, en la que dice que el Segundo Imperio es como la tierra de Jauja para los hombres de negocio, es un momento de relajación y dilapidación en el que las ocupaciones preferidas son el dinero y el sexo, coronados por una necesidad de exteriorización de la riqueza obtenida.

Los personajes de esta clase que, frente a la amoralidad reinante, tienen a gala mostrar una honra y unos principios de los que en realidad carecen, son característicos de esta saga. Así en Pot-Bouille, Mme Josserand, una de las inquilinas de la casa, tiene a gala tratar de la honra de sus sirvientas: il fallait être absolument intratable sur la question de moralité; ... si elle gardait son torchon d'Adèle ..., c'était à cause de l'honnêteté profonde de cette cruche-là28; M. Duveyrier, consejero en el Tribunal de Apelación, hombre digno y justo, se vanagloria de ser duro con las personas que cometen un infanticio o cualquier acto inmoral -por este hecho, va a ser nombrado presidente de la Cámara y se le va a condecorar con la Legión de Honor- y, sin embargo, deja que la sirvienta de una vecina, Adèle, de la que él y su hijo Auguste han abusado- L'un et l'autre ... s'en fichaient pas mal, maintenant qu'ils avaient eu le plaisir et qu'elle avait la peine ${ }^{29}$-, tire a su hija recien nacida en un callejón al lado de su casa para poder salvar su honra y su esencial puesto de trabajo: elle enveloppa l'enfant de vieux linge, puis le plia dans deux journaux. Il ne disait rien, son petit coeur battait pourtant...elle put sortir, ... aller poser son paquet dans le passage ${ }^{30}$.

Otro caso lo tenemos en el presidente Grandmorin que, respaldado por su posición social y económica, desata sus impulsos sexuales cometiendo estupro con las mujeres más débiles y que generalmente están bajo su protección. Es el causante de la muerte prematura de Louisette, a causa de sus abusos, y viola a su protegida Séverine a la edad de 16 añoshecho que posteriormente será la causa de su muerte-, casándola posteriormente con otro protegido, para sentirse más liberado, y con derecho a seguir usándola cuando lo crea conveniente ${ }^{31}$.

Eugène Rougon, aunque citado entre los personajes que entran en la nobleza por casamiento, es otro de los personajes que, burgués de nacimiento, asciende a las más altas esferas de la sociedad, por su ambición y por su carencia de moralidad: D'une ignorance crasse, d'une grande médiocrité dans toutes les choses étrangères au maniement des

\footnotetext{
${ }^{28}$ ZOLA, Émile: 1971, Pot-Bouille, Brodard y Taupin, Le livre de Poche, París, p. 427.

${ }^{29}$ Ibidem, p. 415.

${ }^{30}$ Ibidem, p. 426.

${ }^{31}$ Ver ZOLA, Émile: 1972, La bête humaine, Brodard et Taupin, París, p. 26. Aunque Zola no libera del todo al hombre de su culpabilidad en una violación, deja claro también que, generalmente, son las mujeres las que provocan o no impiden el hecho, debido en particular a su educación, a la miseria en que viven o al medio social en que se desarrollan (ver op. cit. Muller-Campbell, 1973).
} 
hommes... (possédait par contre) une flamme de volonté, une passion de la force, dédaigneuse des petits moyens et des petites joies ${ }^{32}$.

En oposición a estos, aparecen otros personajes que están orgullosos y fieles de su honra y se yerguen como defensores de sus principios. Es el caso del padre de Renée Saccard, el magistrado Béraud de Châtel, representante de los valores republicanos -uno de sus antepasados murió por ella-. Al llegar el Imperio dejó su puesto, soñando con un gobierno de justicia y de libertad. Su familia, representante de la alta y acomodada burguesía de París, que destaca por su sobriedad y por su estabilidad, mantiene los sentimientos de dignidad y de honor y las obligaciones morales a que está sujeta ${ }^{33}$.

Finalmente, también aparecen otros que, introducidos en esta vorágina especulativa y en este uso fraudulento del dinero, abandonan sus principios y, una vez en la bancarrota, desnudos física y moralmente, no tienen otra salida que suicidarse. Es el caso del banquero de Marsella, Jordan que: c'était autrefois suicidé, à la suite de spéculations désastreuses ${ }^{34}$.

De entre la enorme variedad de especímenes representados, el personaje masculino más característico de esta clase en la saga es el financiero Aristide Rougon -cambia el apellido por la connotación negativa que el primero tiene de rojo-sangre, idea de mancha-, llamado Saccard ${ }^{35}$, que aparece en dos de las novelas de la serie:

- La Curée $e^{36}$-que ocupa la etapa de formación y de ascensión social-. En esta novela se nos descubre el carácter depravado, vividor y sin escrúpulos del personaje y su falta de apego a todo lo que no sea su ego. Para ello se aprovecha de todo el que se acerca a él y, en particular, de las mujeres.

\footnotetext{
${ }^{32}$ Zola (1971), op. cit. p. 152.
}

${ }^{33}$ No debemos olvidar que para Zola, el sistema republicano será el encargado de recoger la amoralidad, la corrupción y el régimen de vicios imperante en el Imperio, y deberá levantar de nuevo el país, lejos de la ostentación y del derroche de la época imperial.

${ }^{34}$ ZOLA, Émile: 1972, L'Argent, Brodard y Taupin, París, p. 26.

${ }^{35}$ Leblond analiza a los financieros de este período como: Hommes d'un métier dont la nécessité quotidenne est de réduire d'innombrables familles à la ruine, les pères et les époux au suicide, les enfants à la mendicité, les femmes à la prostitution, ... ne peuvent avoir de coeur, indubitablement (op. cit. p. 115). Esta reflexión es el retrato de este personaje zoliano. Aristide Saccard es la plasmación novelística de la acción financiera de los hermanos Pereire, con la creación, al igual que el personaje zoliano, del Crédit mobilier, que desapareció a causa de una bancarrota, y de Mirès, propietario, al igual que Saccard en L'argent, de los periódicos Journal du Chemin de Fer, Le Pays y Le Constitutionnel. Con respecto al matiz especulativo, Zola lo acerca a G. Haussmann, el hacedor del nuevo París y el desencadenador del furor especulativo y de gasto en que se sumerge todo el gobierno imperial y las clases privilegiadas.

${ }^{36}$ Personificación del derroche por el derroche. Historia de la pasión y de la perversión sexual; es la utilización de una mujer, Renée Saccard -símbolo de la sociedad decadente y representación de todo lo que una mujer no debe ser; usa su cuerpo sólo para el goce, el lujo y el vicio, desdeñando su papel de madre y esposa-, por el marido, Saccard, y por el hijo, Maxime, con el que cae en incesto. Sobre esta obra, espejo fiel de la corrompida sociedad imperial y de la degeneración burguesa, surgen múltiples acusaciones, llegando incluso a ser llamado Zola por el Procurador de la República para que deje de publicarla, ya que ofende al pudor público. El 9 de noviembre de 1871, aparece en Le Figaro, una carta bajo el pseudónimo de Covielle que ataca a la obra, al autor y a la República: J'ai dû reconnaître qu'il fallait vivre en république pour qu'on tolérât une publication qui, sous un gouvernement regulier, eût certainement conduit son auteur sur les bancs de la correctionnelle (Notice sur les origines de La curée, edición Gallimard, París, 1981). 
Primeramente, apoyándose en su madre, se casa con Angèle Sicardot por la dote, ya que entre sus habilidades no están las puramente laborales. Una vez que gasta el dinero de su mujer, ayudado esta vez por su hermana Sidonie, se va a París y se aprovecha de la situación de su hermano Eugène. El mismo día en que muere su mujer, firma el contrato de su nuevo matrimonio con Renée Béraud de Châtel por dinero. La etapa de explotación se acentúa con esta segunda mujer y acaba cuando la expolia física y mentalmente, empujándola incluso al incesto con su hijo Maxime.

- L'Argent ${ }^{37}$-donde se desarrolla su ensoñación especulativa-. Es la etapa en la que después de su ruina: il en était là, après la débâcle qui, en octobre l'avait forcé une fois de plus à liquider sa situation, à vendre son hôtel du parc Monceau, pour louer un appartement $\hat{t}^{\hat{8}}$; resurge, como el ave Fenix, de sus propias cenizas. Sin embargo con cada fracaso una esperanza de victoria se le escapaba de las manos: Il tombait une fois encore, et de très haut: il lui semblait être détrônê ${ }^{39}$. Renace de nuevo como un luchador nato y decide, para alcanzar el máximo auge económico: Se battre, être le plus fort dans la dure guerre de la spéculation, manger les autres pour ne pas qu'ils vous mangent ${ }^{40}$; pero todo esto será al mismo tiempo el comienzo de su cercana destrucción después de la bancarrota de la Banque Universelle, por la que fue condenado junto a Hamelin: à cinq années d'emprisonnement et à trois mille francs d'amende ${ }^{41}$.

Como siempre, para conseguirlo, se apoya también, además de en su hermana Sidonie, en otras mujeres para sacar el mayor rendimiento de ellas, como es el caso de la princesa de Orviedo, mujer de inmensa fortuna, de la que es consejero y director de l'Oeuvre du Travail.

Una de sus múltiples víctimas es la condesa de Beauvilliers -miembro de la aristocracia decadente y empobrecida- que, animada por la forma rápida de hacer dinero de Saccard, invierte en la Bolsa y se arruina: Leur fortune entière se trouvait fondue... C'était l'indigence du soir au lendemain ${ }^{42}$.

La única que desinteresadamente se ocupa de él, Caroline Hamelin, cede en un principio ante sus evidentes encantos, pero finalmente reacciona y no se deja arrastrar por su vorágine especulativa, siendo la causante, de manera indirecta, por la interferencia de su hermano Georges, de su bancarrota y de toda la sociedad de la Banque universelle, sobre la que influye.

Este personaje, clásico representante de la dominante fuerza masculina, sale indemne en la primera de las novelas citadas, pero es sancionado junto a toda la sociedad que él

\footnotetext{
${ }^{37}$ Zola pinta, a través de su personaje Saccard, el mundo de especulación y de derroche de la Bolsa y el crack de l'Union Nationale.

${ }^{38}$ Ibidem, p. 10.

${ }^{39}$ Ibidem, p. 65.

${ }^{40}$ Ibidem, p. 66.

${ }^{41}$ fuidem, p. $480-489$.

42 Ibidem, p. 465.
} 
representa en la segunda, dando con ello el escritor un fin moralizador negativo a este tipo de vida corrupta y degenerada.

Este elemento masculino, meticuloso en extremo, no hace ningún movimiento sin planificar primero los rendimientos y las ganancias que va a obtener. Especulador nato, gasta el dinero de todos los que están a su alrededor, sumiéndolos en la ruina económica, social y física, sacando siempre un provechoso rendimiento personal o social. Zola lo define como: appetit d'argent.

De entre todos los personajes representados de esta clase, vamos a concluir este apartado con el retrato que nos da Zola en La curée, del emperador Napoleón III, fiel reflejo de la imagen disoluta de la sociedad y de su etapa imperial: Elle le trouva petit, les jambes trop courtes,... le visage blême, sa paupière lourde et plombée qui retombait sur son oeil mort. Sous ses moustaches, sa bouche s'ouvrait, mollement, tandis que son nez seul restait osseux dans toute sa face dissoute ${ }^{43}$.

$c_{0}=$ El clero. Como cualquier escritor naturalista que se precie, Zola no explica la condición humana y los problemas que de ella emanan por medio de factores sobrenaturales -ya que esto es una práctica común en ciertas sociedades como medio de ocultar su ignorancia y su falta de razonamiento científico-, sino que se fija en los materiales, estudiando al hombre como un producto evolutivo de la historia natural.

Zola es creyente, pero se aleja cada vez más de los pincipios de la Iglesia Católica, representante de unos dogmas que ofenden a la razón, considerándola por ello retrógrada, oscurantista y predicadora de una religión del miedo y del pesimismo: es algo contra natura.

Zola es, como Rousseau, partidario de una religión natural que basa su religiosidad en unas relaciones directas entre el creyente y el Ser Supremo, desarrollada esta relación en el medio natural. Su moral se centra en la ambición para conseguir unos fines prefijados, centrada en un esfuerzo personal: el trabajo, única fuerza que puede liberar al hombre de la miseria y del destino a que estaba sujeto desde su nacimiento.

En el siglo XIX, la Iglesia era muy importante en Francia y, como hemos ya visto anteriormente, el poder político se amparaba en ella para llegar más rápidamente a la sociedad. El apego de los miembros de la Iglesia por el poder, la necesidad de ejercer su autoridad y la negación, como pecaminoso, de todo lo que era natural, le llevaron a condenar el catolicismo y a considerar a los sacerdotes, por el hecho de ser célibes, como engendros o seres antinaturales. Zola nos muestra reiteradamente al sacerdote como símbolo de lo negativo; esto es debido al color negro de su sotana: Les soutanes, ça porte malheur ${ }^{44}$.

El negro es un color negativo dentro del imaginario humano y es particularmente nocivo en el universo zoliano, ya que es frecuentemente connotado como significante de las fuerzas que nos sumergen en la oscuridad, en lo oculto, en lo misterioso.

\footnotetext{
${ }^{43}$ La curée, op. cit. p. 188.

${ }^{44}$ ZOLA, Émile: 1971, La conquête de Plassans, Fasquelle, Le livre de Poche, n1 384, París, p. 68.
} 
En casi todos sus obras aparece un sacerdote que intenta conseguir poder por su influencia entre las mujeres -no olvidemos que Zola, misógino en ciertos aspectos de su pensamiento, consideraba a la mujer como menos fuerte que el hombre, menos resistente y por ello más propensa a dejarse caer en este embaucador mundo simbólico- y entre los jóvenes.

De entre los sacerdotes más perversos destaca el abate Faujas, personificación de la hipocresía, representante de la sumisión de la Iglesia al Estado y de la ambición política de los sacerdotes católicos. Es un hombre ávido de poder, que causa la destrucción física y moral de todo lo que se pone a su alrededor para alcanzar la máxima dominación posible.

Zola le atribuye una doble simbología: la del águila, el único animal cuyo enemigo es él mismo, y la del cardo, ya que, al igual que este vegetal, tiene elementos urticantes que hacen que nada pueda acercarse a él para devorarlo. Lo caracteriza con las siguientes atributos: ... grand, fort, figure à larges traits, ...teint terreux,... il respire la force avant tout,... un fort tempérament, un ambitieux, qui contient ses appétits ${ }^{45}$, pero lo endurece más aún a medida que va aumentando su poder: Sa face redevenue terreuse avait des regards d'aigle; ses grosses mains se levaient, pleines de ménace et de châtiments. La ville fut positivement terrifiée... personne n'osait risquer le moindre mot équivoque sur son compte $^{46}$.

En esta obra, rica en personajes eclesiásticos aparecen otros sacerdotes que representan diferentes facetas del mundo eclesiástico. El vicario Fenil, representante del oscurantista clero romano: Un terrible homme, plat et pointu comme un sabre... il fallait devenir l'ami du grand vicaire, si l'on voulait être bien reçu à l'évêchét7 ${ }^{47}$ el abate Bourrette, símbolo de la bondad y de las profundas y ancestrales virtudes de la Iglesia y el abate Surin, secretario del obispo, joven rubio y sonrosado, sin personalidad, símbolo del buen comer y del buen beber -imagen clásica y perversa de la personalidad sacerdotal-.

Zola, en sus notas preparatorias, caracteriza a los cuatro sacerdotes de la siguiente forma: Fenil est pour Rome. Faujas pour Paris, Bourrette pour Dieu et Surin pour rien ${ }^{48}$

Otra faceta negativa de la religión la representa el hermano Archangias, en La faute de l'abbé Mouret. Su educación cerrada en los principios religiosos más obsoletos, le cierra los ojos a todo lo que no sea el mundo eclesiástico de muerte y claustración. Sólo acepta a Dios, negando el culto a la Virgen, por la relación que tiene, al ser mujer, con el pecaminoso mundo femenino. Aparece de nuevo aquí la misoginia del autor que en boca de Archangias considera a la mujer como la personificación del espíritu del mal. Zola piensa que su motivación primordial para introducirse en el mundo de la religión es: pour éviter la

\footnotetext{
${ }^{45}$ Notas preliminares a La conquête de Plassans, edición de La Pléiade, p. 1657.

${ }^{46}$ La conquête de Plassans, pp. 376-378.

${ }^{47}$ Ibidem, pp. 51 y 72.

${ }^{48}$ GUILLEMIN, Henri: 1964. Présentation des Rougon-Macquart, Gallimard, París, p. 63.
} 
bêche. Entêté catholique par étroitesse de cerveau,... représente le Dieu de la colère.... La saleté du célibat, l'eunuque dégoûtant ${ }^{49}$.

En la misma obra, frente a este sacerdote desnaturalizado, aparece la figura del abate Mouret, representante de la caridad y del amor, que ocila entre su faceta de hombre vitalista, símbolo de la fuerza natural, y de sacerdote, símbolo de la muerte: C'est l'histoire d'un homme frappé dans sa virilité par une éducation première, devenu être neutre, se réveillant homme à vingt-cinq ans, dans les sollicitations de la nature, mais retombant fatalement à l'impuissance ${ }^{50}$.

Las ideas negativas sobre la religión cambian en Zola al final de su vida, pero no así sus ideas sobre el clero y el sacerdocio en particular; esto se refleja en Les trois villes, y en su personaje principal el abate Pierre Froment.

Este personaje, reflejo de las ideas menos pesimistas del nuevo Zola -motivadas por su relación con Jeanne Rozerot y por el nacimiento de sus dos hijos-, cree que el rejuvenecimiento del catolicismo debe basarse en la juventud exultante del cristianismo primitivo y, de este modo, Cristo, como elemento expiatorio, volverá de nuevo sus ojos sobre la humanidad que sufre, siendo el germen de una religión renovada que será la esperanza de la sociedad futura.

En Rome, como oposición a este catolismo de muerte y de pecado, Zola hace una correlación entre las cerremonias católicas de adoración al Papa y los actos de idolatría y no comprende la riqueza derrochada en San Pedro y en la corte papal, frente al frío, la pobreza y la soledad de las catacumbas de lo antiguos cristianos.

d.- El proletariado. Es la clase representativa del pueblo, para Zola es el símbolo de la fuerza y del trabajo y el germen de la regeneración social y de la sociedad futura.

A lo largo de toda la saga opone el personaje trabajador, honrado y serio, al que se hunde en la holgazonería y en los vicios, generalmente en el alcohol.

En primer lugar tenemos L'Assommoir, es la obra en la que se nos ofrece de forma más evidente, un abanico de actantes, que engloban todas las particularidades de los elementos masculinos en Zola. Nos encontramos con un Coupeau primeramente sano y natural pero degradado rapidamente por el medio y el alcohol: agréable quand il est jeune, ... d'un toupet infernal, ... gai, rigolo,... s'encanaillant rapidement... défiguré par l'ivresse, s'abetissant,... se noyant dans le vin... Une décadence d'homme ${ }^{51}$; frente a Goujet, el arquetipo del trabajador ideal, sano, honrado y sin vicios decadentes; para él el alcohol es el peor enemigo del trabajador: ...le bon ouvrier, le beau forgeron ${ }^{52}$. A ellos dos hay que añadir un tercer espécimen de trabajador, Lantier, más bien un anti-trabajador, un zángano, el seductor nato, ya que su meta es vivir como un burgués a costa de los demás y, en

\footnotetext{
${ }^{49}$ Notas preliminares a la edición de La faute de l'abbé Mouret, edición de La Pléiade, p. 1691.

${ }^{50}$ Ibidem, p. 1679.

${ }^{51}$ Henri Mitterand, notas preliminares a la aparición de L'Assommoir, edición de La Pléiade, p. 1547.

${ }^{52}$ Ibidem, p. 1547.
} 
particular, de las mujeres, cambiándolas cuando no puede ya sacar más provecho de ellas: l'ouvrier... qui... parle politique, lit les journaux... Très paresseux, affectant des airs supérieurs, se faisant entretenir ${ }^{53}$.

Pero este trabajador, agobiado por el duro trabajo y, en particular, por el paro, descubre como una posible vía de escape, las ideas socialistas y anarquistas y se entrega a ellas.

Los revolucionarios proletarios de Zola son soñadores, viven para conseguir su ilusión, el triunfo de su clase y la desaparición del patrón: Chez tous les révolutionnaires de Zola, la révolution est... la poursuite d'une chimère où se complait la sensibilité blessée, une exigence morale devant l'injustice du monde, un rêve compensateur de bonheur universel ${ }^{54}$.

En Germinal, aparecen diversos tipos connotados casi todos con un marcado matiz político: Souvarine, es un burgués reconvertido a anarquista proletario, seguidor de las ideas destructivas de Bakunin y que predica la abolición de los estados y las clases sociales; Pluchart, socialista, trabajador de la política, opuesto al destructivismo de Souvarine, se fija como meta, liberar a los trabajadores por medio de la fuerza de la afiliación sindical; Rasseneur, sindicalista, de ideas socialistas, partidario de la negociación y opuesto al principio de la fuerza por la fuerza; Etienne Lantier, socialista intransigente y sindicalista, predispuesto a la revuelta para luchar contra el dominio del capital y conseguir una sociedad más sana e igualitaria para los trabajadores, y Maheu, el trabajador nato, mártir del trabajo y de la superación, que muere a manos de la guardia enviada por el patrón, por defender sus principios de trabajador en libertad.

Las ideas socialistas de Zola son tales que convierte, por la mano de Octave Mouret en $A u$ Bonheur des Dames, el gran almacén parisino en una especie de falansterio donde se trabaja, se come, se duerme e incluso están cubiertas las necesidades médicas.

Pero los sueños socialistas del autor llegan a cristalizar al final de su producción, en Travail, novela idealista por excelencia, donde nos muestra un marco de vida ideal que va a ser hecho realidad. De la mano del protagonista, Luc Froment, comunista evolucionista, y con la ayuda de su rico amigo Jordan -engrandecido y santificado por el trabajo-, crean: en face de l'Usine capitaliste, gâcheuse d'ouvriers, une usine syndicale dont les bénéfices soient repartis entre les manoeuvres, l'intelligence directrice et le capitall ${ }^{55}$.

Mención especial, en este apartado, y para connotar el papel negativo que también puede tener el trabajo, corresponde a los trabajadores agrarios de La terre, y en particular a los elementos masculinos, en los que el poder de la tierra y la necesidad de su posesión les hace desplegar una serie de actos violentos, despierta sus instintos de animal sanguinolento que emanan de la degradación moral de sus personajes y de la interferencia del medio en

\footnotetext{
${ }^{53}$ Ibidem, p. 1547.

${ }^{54}$ GUEDJ, Aimé: 1968, Les révolutionnaires de Zola, Fasquelle, Les Cahiers Naturalistes, París, n1 36, p. 127.

${ }^{55}$ LEBLOND, Marius-Ary, 1905, p. 285.
} 
ellos, despertando y exacerbando su avaricia, su codicia y su agresividad sexual; el hombreanimal reaparece de nuevo ${ }^{56}$.

A modo de conclusión, evidenciamos que, de todo lo expuesto en este trabajo sobre el hombre, lo que nos queda perfectamente claro es que, para este novelista e ideólogo francés -al igual que para otros escritores y pensadores anteriores, posteriores y cercanos a este período-, a pesar de las consideraciones políticas, religiosas o laborales, desde que el hombre se situó en medio de la naturaleza, su psicología y su fisiología han estado en continua evolución; sin embargo hay una idea, para el elemento masculino quizás un principio, que no ha evolucionado ni un ápice, es que él es el centro de la creación, y que los demás seres creados, incluida la mujer, giran en torno a su persona. De ahí, la lucha inequívoca, continua y desenfrenada entre cada uno de los hombres por dejar patente su superioridad, frente a los otros machos de su especie.

Alberto Guallart en su artículo, La psicología termina por ser reducida a escombros, aclara estas ideas exclusivistas y subliminantes del hombre, mostrando que cada ser humano intenta crear en su entorno un mundo objetivo interpersonal, al que accede al alcanzar un nivel superior, estableciendo, en este caso, una transposición directa entre el hombre y Dios:

Todos los hombres quieren ser de mayores Dios. No un dios menor, pequeñito, tribal y compañero de otros dioses igualmente menores, tribales y pequeñitos. El hombre, cualquier hombre, quiere ser Dios ${ }^{57}$.

\section{BIBLIOGRAFÍA.}

AGULHON, Maurice: 1973, 1848 ou l'apprentissage de la république, 1848-1852. Nouvelle Histoire de la France contemporaine, vol. 8, Seuil, París.

BORIE, Jean: 1971, Zola et les mythes ou de la nausée au salut, Seuil, París.

BUVIK, Per: 1975, Nana et les hommes, Les cahiers naturalistes, Fasquelle, París, pp. 105124.

DETHLOFF, Uwe: 1987, Emancipation sociale et patriarcat utopique, Kwartalnik Neofilologiczny, Polonia, vol. 34, n1 2, pp. 131-144

HEMMINGS, F. W. J.: 1966, Émile Zola, Clarenton Press, Oxford.

JARDIN, A. y TUDESQ, A. J.: 1973, La France des notables. L'évolution générale, 1815 1848. Nouvelle Histoire de la France contemporaine, vol. 6, Seuil, París.

\footnotetext{
${ }^{56}$ Confrontar: LOPEZ SAEZ, Raquel: 1977, Algunas motivaciones y aspectos de la violencia en La Terre, de Emilio Zola y en La Barraca, de Vicente Blasco Ibañez, Revista de Filología Moderna, Madrid, n1 59-60-61, noviembre 1976, junio 1977, pp 265-300.

${ }^{57}$ Artículo aparecido en la revista cultural del Correo de Andalucía, 17 de noviembre de 1995.
} 
LEBLOND, Marius-Ary: 1905, La société française sous la troisième République, d'après les romanciers contemporains, Félix Alcan, París.

MAYEUR, Jean-Marie: 1973, Les débuts de la IIle. république, 1871-1898. Nouvelle Histoire de la France contemporaine, vol. 10, Seuil, París.

MOREAU, Thérèse: 1983, Noces d'or: l'économie anti-malthusienne dans l'oeuvre de Zola, Romantisme, n1 40, pp. 153-165.

MULLER-CAMPBELL, Denise E.: 1973, Le thème de la culpabilité masculine dans l'oeuvre de Zola, Les cahiers Naturalistes, Fasquelle, París, pp. 165-181,

PLESSIS, Alain: 1973, De la fête impériale au mur des fédéres, 1852-1871, Nouvelle Histoire de la France contemporaine, vol. 9, Seuil, París.

RUBÉRIOUX, Madeleine: 1975, La république radicale, 1898-1914. Nouvelle Histoire de la France contemporaine, vol. 11, Seuil, París.

ZOLA, Émile: 1971, Pot-Bouille, Fasquelle, Le livre de Poche, n1 247, París.

ZOLA, Émile: 1971, La conquête de Plassans, Fasquelle, Le livre de Poche, n1 384, París.

ZOLA, Émile: 1971, La faute de l'abbé Mouret, Fasquelle, Le livre de Poche, n1 69, París.

ZOLA, Émile: 1972, L'argent, Fasquelle, Le Livre de Poche, París. 